\title{
Determination of Optimum Drying Temperature Profile by Iterative Learning Control (ILC) Method to Obtain a Desired Moisture Content in Tablets
}

Nahid Sanzida*

Department of Chemical Engineering, Bangladesh University of Engineering and Technology (BUET), Dhaka-1000, Bangladesh. Article Info: Submitted on March 10, 2018, Accepted on May 25, 2018.

\begin{abstract}
:
The paper presents an industrial case study example to evaluate the performance of the linear time varying (LTV) perturbation model based iterative learning control (ILC) in a pilot scale batch system. The operating data based strategy applied here is based on utilizing the repetitive nature of batch processes to update the operating trajectories using process knowledge obtained from previous runs and thereby providing a convergent batch-tobatch improvement of the process performance indicator. The method was applied to determine the required drying temperature of Paracetamol granules to obtain desired moisture content at the end of the batch. After granulation operations, Paracetamol granules were dried in a fluid bed dryer in the pilot plant laboratory of GlaxoSmithKline Bangladesh Limited, Chittagong, Bangladesh. These results demonstrate the potential of the ILC approach for controlling batch processes without rigorous process models.
\end{abstract}

Keywords: Batch process, Iterative learning control, LTV perturbation model, Moisture content, Tablet manufacturing.

\section{Introduction}

Tablet is a solid unit pharmaceutical dosage form consisting of one or more active ingredients (AI) and excipients, prepared by either compression or moulding of the powder mixture. Excipients are added chiefly to serve as diluents (filler), binders, disintegrating agent, granulating agents, glidants (flow aids) and lubricants to ensure efficient tableting ${ }^{1}$. Other excipients like sweeteners, dyes, flavors and pigments are added either to increase the taste or appearance of the tablets ${ }^{2}$.

The main ingredients of Paracetamol tablet are Acetaminophen powder along with other powdered excipients. The powder should posses good flow property to have uniformity of weight of the tablet. The flow property of powder depends upon moisture content of the powder as well as particle size, particle shape, porosity and density. Water interacts with pharmaceutical solids at virtually all stages of manufacture. Therefore, water-powder interaction is a major factor in the formulation, processing, and performance of solid dosage forms.

This moisture content is important for the mechanical strength of the tablet. However, according to the literature, as the moisture content of pharmaceutical substances increases the tablets' tensile strength increases (specifically at low moisture contents), reaches a maximum, and then decreases (specifically at higher moisture content). Therefore, it is important to know the optimal moisture content for the formation of strong tablets.

Within the pharmaceutical industries it is well established that Acetaminophen with $2 \%$ moisture content gives tablet of optimum strength ${ }^{3}$. This eventually leads to the determination of the optimum drying temperature to reach the desired moisture content.

The current practice in pharmaceutical industries for moisture content determination is based on off-line loss on drying (LOD) techniques ${ }^{4}$. LOD techniques requires frequent stopping of the dryer during the operation to check the moisture content. This results in significantly increased cycle times. Samples collected manually are also susceptible to changes in physical conditions like humidity and segregation leading to inaccurate moisture analysis. In addition, generally there is a delay before analysis results are available to the operator that causes processing decisions, like endpoint determination, to be made without optimal product moisture information. 


\section{Chemical Engineering Research Bulletin 20(2018) 1-7}

Within the existing pharmaceutical industrial practice framework, the exact knowledge of drying temperature against a fixed time to reach the desired moisture content is important. This saves companies huge energy cost, eliminate the damage of product due to over-drying, and increase the overall efficiency of the drying process.

In this situation, applying a batch-to-batch control approach is much practical. Batch-to-batch control approach exploits the repetitive nature of batch processes to update the process operating trajectories using process knowledge obtained from previous batch runs. This is the main idea of iterative learning control (ILC). ILC improves transient tracking performance of a system that executes the same task repeatedly over a fixed time interval ${ }^{5}$. However, it can also be applied to find the transient setpoint to achieve a desired endpoint performance. ILC has been applied successfully for the systematic design of supersaturation controlled batch cooling crystallization processes ${ }^{6}$. Batch crystallization is important in the pharmaceutical industry as a separation process for the intermediates and often serves as the final step in the manufacture of active pharmaceutical ingredients (APIs) ${ }^{7}$.

In this study an LTV perturbation model based ILC was applied to determine the drying temperature to obtain the desired moisture content in Parapyrol tablet granulates at the end of the batch. The industrial case study was carried out in GlaxoSmithKline Bangladesh Limited, Chittagong, Bangladesh. The study shows that the proposed ILC strategy can calculate the required drying temperature, eliminate the within batches measurement of moisture contents and gives the desired moisture content at the end of the batch under a fixed batch time

\section{Iterative Learning Control (ILC) in Batch Chemical Processes}

In the batch-to-batch control approach variations must be considered on two time-scales. As shown on Figure 1, variations within and between batches can be considered leading to an optimization problem on two time scales ${ }^{8}$. However, during a batch, within batch measurements are often unavailable or adjustment to the operating conditions cannot be made due to limited online sensors or actuators. Hence, batch-to-batch improvement is still dependent on learning from the information obtained usually from after-batch laboratory analyses. In this situation the within batch measurements (if available) are used to estimate model based parameters and states. The updated model is then used in an ILC framework to improve the future operating recipe (see Figure 2).

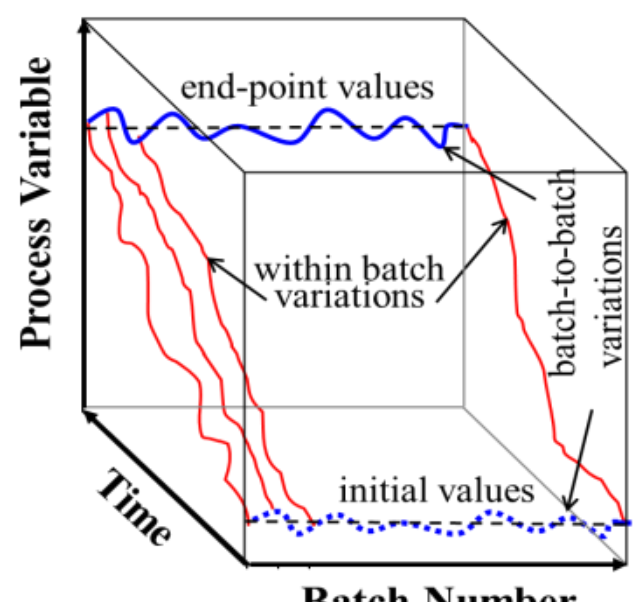

Figure 1: Schematic representation of the dynamic two-time scale variations in batch control $^{8}$.

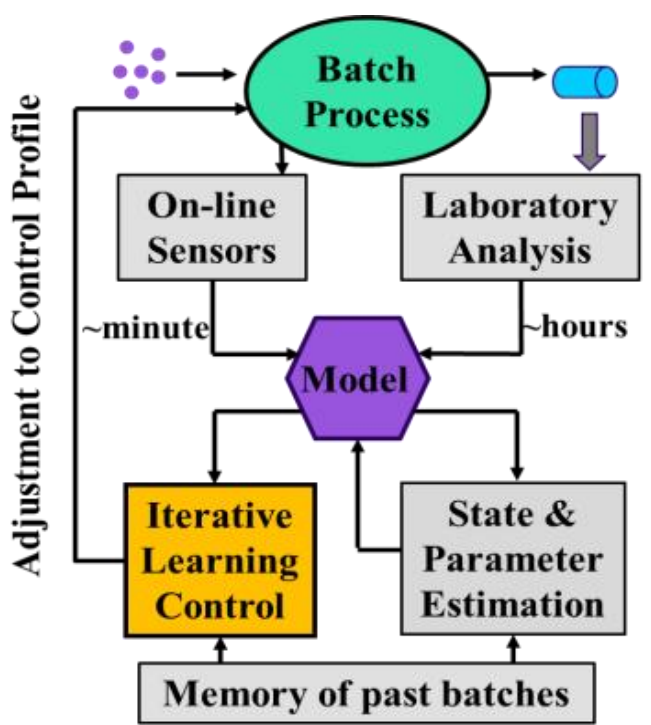

Figure 2: Structure of the ILC framework ${ }^{8}$.

\section{Linear Time Varying (LTV) Perturbation Model}

The methodology applied is based on the approach proposed by ${ }^{9}$ which is an ILC scheme based on linear time varying (LTV) perturbation models. Typically the input/output trajectories in batch processes are inherently nonlinear and time varying. However, the concept of using perturbation variables removes process nonlinearity by subtracting time varying nominal trajectories from the batch operation trajectories. If we consider the following nonlinear

(CBangladesh Uni. of Engg.\&Tech 2 


\section{Chemical Engineering Research Bulletin 20(2018) 1-7}

function between input $\mathbf{X}_{b}(t)$ and output $\mathbf{Y}_{b}(t)$ in the matrix form,

$\mathbf{Y}_{b}=\boldsymbol{\Psi}\left(\mathbf{X}_{b}\right)+\mathbf{n}_{b}$

where, $\boldsymbol{\Psi}(\cdot)$ is the nonlinear static function between the input and output and $\mathbf{n}_{b}$ is the vector of measurement noise. For the system (1), an LTV perturbation model $\mathbf{L}_{\mathrm{s}}$ is developed by linearizing the nonlinear model along the nominal trajectories. Initially several sets of historical process operating data are collected and the input-output data matrices, $\mathbf{\Omega}_{x}^{0}=\left[\mathbf{X}_{1}, \mathbf{X}_{2}, \ldots, \mathbf{X}_{\mathrm{H}}\right]^{\mathrm{T}}$ and $\boldsymbol{\Omega}_{y}^{0}=\left[\mathbf{Y}_{1}, \mathbf{Y}_{2}, \ldots, \mathbf{Y}_{\mathrm{H}}\right]^{\mathrm{T}}$

respectively, are constructed, where, $H$ is the number of historical batches. From these data, the best performing trajectories are selected as the nominal trajectories $\left(\mathbf{X}_{\mathrm{s}}, \mathbf{Y}_{\mathrm{s}}\right)$. At any time $t$, the perturbation variables for the bth batch are calculated as $\overline{\mathbf{X}}_{b}=\mathbf{X}_{b}-\mathbf{X}_{\mathrm{s}}$ and $\quad \overline{\mathbf{Y}}_{b}=\mathbf{Y}_{b}-\mathbf{Y}_{\mathrm{s}}$. Linearizing the nonlinear model (1) around the nominal trajectories gives,

$\mathbf{Y}_{b}=\mathbf{Y}_{\mathrm{s}}+\left.\frac{\partial \Psi\left(\mathbf{X}_{b}\right)}{\partial \mathbf{X}_{b}}\right|_{\mathbf{X}_{\mathrm{s}}}\left(\mathbf{X}_{b}-\mathbf{X}_{\mathrm{s}}\right)+\mathbf{m}_{b}+\mathbf{n}_{b}$

where, $\quad \mathbf{m}_{b}=\left[m_{b}^{\mathrm{T}}(1), m_{b}^{\mathrm{T}}(2), \ldots, m_{b}^{\mathrm{T}}(N)\right]^{\mathrm{T}} \quad$ is the sequence of model errors of $N$ observations due to linearization. The LTV perturbation model and corresponding absolute model prediction of Equation (2) are,

$\overline{\mathbf{Y}}_{b}=\mathbf{L}_{s} \overline{\mathbf{X}}_{b}+\mathbf{d}_{b}$

$\hat{\mathbf{Y}}_{b}=\mathbf{Y}_{\mathrm{s}}+\hat{\mathbf{L}}_{\mathrm{s}} \overline{\mathbf{X}}_{b}$

The tracking errors of the actual process and of the predicted perturbation model are $\mathbf{e}_{b}=\mathbf{Y}_{\mathrm{d}}-\mathbf{Y}_{b}$ and $\hat{\mathbf{e}}_{b}=\mathbf{Y}_{\mathrm{d}}-\hat{\mathbf{Y}}_{b}$, respectively. The transfer function $\hat{\mathbf{L}}_{\mathrm{s}}$ is predicted according to the steps of Equation (5), for $i=1,2, \ldots, N$, number of observations per batch and $h=1,2, \ldots, H$ is the number of historical batches,

$\bar{y}_{h}(i)=y_{h}(i)-y_{\mathrm{s}}(i), \quad \bar{x}_{h}(i)=x_{h}(i)-x_{\mathrm{s}}(i), \quad$ and

$\mathbf{u}_{h}(i)=\left[\bar{x}_{1}(i), \bar{x}_{2}(i), \ldots, \bar{x}_{h-1}(i), \bar{x}_{h}(i)\right]^{\mathrm{T}}$
If, $\mathbf{V}_{0}^{i}=\left[\begin{array}{c}\bar{y}_{1}^{\mathrm{T}}(i) \\ \bar{y}_{2}^{\mathrm{T}}(i) \\ \vdots \\ \bar{y}_{H}^{\mathrm{T}}(i)\end{array}\right]$ and $\mathbf{U}_{0}^{i}=\left[\begin{array}{c}\mathbf{u}_{1}^{\mathrm{T}}(i) \\ \mathbf{u}_{2}^{\mathrm{T}}(i) \\ \vdots \\ \mathbf{u}_{H}^{\mathrm{T}}(i)\end{array}\right]$

then, the system, $\hat{l}_{i}$ is estimated at each observation by the least squares method as, $\hat{l}_{i}=\left(\mathbf{U}_{0}{ }^{i \mathrm{~T}} \mathbf{U}_{0}{ }^{i}\right)^{-1} \mathbf{U}_{0}{ }^{i \mathrm{~T}} \mathbf{V}_{0}{ }^{i}$ and $\hat{\mathbf{L}}_{\mathrm{s}}$ is obtained as, $\hat{\mathbf{L}}_{\mathrm{s}}=\left[\hat{l}_{1}, \hat{l}_{2}, \ldots, \hat{l}_{N}\right]^{\mathrm{T}}$. After completion of the $b^{\text {th }}$ batch run, prediction errors between off-line-measured or analyzed product qualities and their model predictions can be calculated as, $\boldsymbol{\varepsilon}_{b}=\mathbf{Y}_{b}-\hat{\mathbf{Y}}_{b}$. The absolute modified model prediction is defined as, $\tilde{\mathbf{Y}}_{b+1}=\hat{\mathbf{Y}}_{b+1}+\boldsymbol{\varepsilon}_{b}$. The tracking error of the modified prediction of the perturbation model is defined as, $\tilde{\mathbf{e}}_{b}=\mathbf{Y}_{\mathrm{d}}-\tilde{\mathbf{Y}}_{b}$. In ILC, it is desired that, $\lim _{b \rightarrow \infty}\left\|\mathbf{e}_{b}\right\|^{2} \rightarrow \min _{\mathbf{X}}\|\mathbf{e}\|^{2}$. Finally, the following quadratic objective function is formulated based on the minimization of the predicted tracking errors,

$J_{b+1}=\min _{\Delta \mathbf{X}_{b+1}} \frac{1}{2}\left[\tilde{\mathbf{e}}_{b+1}{ }^{\mathrm{T}} \mathbf{O} \tilde{\mathbf{e}}_{b+1}+\Delta \overline{\mathbf{X}}_{b+1}{ }^{\mathrm{T}} \mathbf{P} \Delta \overline{\mathbf{X}}_{b+1}\right]$

where, $\mathbf{O}$ and $\mathbf{P}$ are weighting matrices based on output performance and input change, respectively. This objective function should be solved upon completion of the bth batch to update the input trajectory for the $(\mathrm{b}+1)^{\text {th }}$ batch as, $\mathbf{X}_{b+1}=\mathbf{X}_{b}+\hat{\mathbf{K}}_{b} \mathbf{e}_{b}$, where,

$\hat{\mathbf{K}}_{b}=\left[\hat{\mathbf{L}}_{\mathrm{s}}^{\mathrm{T}} \mathbf{O} \hat{\mathbf{L}}_{\mathrm{s}}+\mathbf{P}\right]^{-1} \hat{\mathbf{L}}_{\mathrm{s}}^{\mathrm{T}} \mathbf{O}$, is the calculated control action.

\section{Parapyrol Tablet}

The Paracetamol tablet manufactured by GlaxoSmithKline Bangladesh Limited was initially marketed under generic name of 'Paracetamol Tablet' and later with trade a name from 1993 as 'Parapyrol tablets'. Parapyrol is a registered trademark product of GlaxoSmithKline Bangladesh Limited. The formulation has been adopted from Speke document, UK dated 3 March 1983. Table 1 lists the AI and excipients used in the formulation of Parapyrol tablets. 


\section{Chemical Engineering Research Bulletin 20(2018) 1-7}

Table 1: Ingredients of Parapyrol Tablet.

\begin{tabular}{|c|c|}
\hline Active Ingredient (AI) & Functions \\
\hline Paracetamol & $\begin{array}{l}\text { Analgesic and } \\
\text { Antipyretic }\end{array}$ \\
\hline Excipients & Function \\
\hline $\begin{array}{l}\text { Maize starch, Pregelatinised } \\
\text { (Amigel) BP/EP/ USNF }\end{array}$ & Binder \\
\hline Maize starch, BP/EP/ USNF & $\begin{array}{l}\text { Diluent, } \\
\text { Disintegration }\end{array}$ \\
\hline Potassium Sorbate & $\begin{array}{l}\text { Antimicrobial } \\
\text { Preservative }\end{array}$ \\
\hline Stearic acid (Powder) & Lubricant \\
\hline
\end{tabular}

\section{Manufacture of the Tableting Blend}

Tablet manufacturing process includes different stages including, Dispensing (weighing and measuring), Sizing, Powder blending, Granulation, Drying, Tablet compression and Packaging.

In the tablet pressing process, the main objective is to ensure that the appropriate amount of $\mathrm{AI}$ is present in each tablet. Hence, all the ingredients should be wellmixed. Two basic techniques that are used to granulate powders for compression into a tablet are dry granulation and wet granulation ${ }^{2}$. Dry granulation involves slugging tool or a roller compactor to create granules by light compaction of the powder blend. This process is often used for heat and moisture sensitive products. Wet granulation involves a liquid binder to lightly agglomerate the mixture. After wet granulation, the damp mass is then screened through a mesh to form pellets or granules. The granules are then dried in conventional tray-dryer or fluid-bed dryer (FBD). The dried granules are passed through a screen of smaller size than the one used for the wet mass to create granules of uniform size.

However, this study is mainly focused up to the point of mixing and drying of tablet blend.

\section{Effect of Moisture Content on Tablets}

Moisture content is usually determined by loss on drying (LOD) method. Formula for calculating moisture content in percentage is as follows,

$$
\% \text { MoistureContent }=\frac{(\text { Loss in weight })}{(\text { Initial Weight })} \times 100
$$

The amount of water associated with a solid at a particular relative humidity $(\mathrm{RH})$ and temperature depends on its chemical affinity for the solid and the number of available sites of interaction, surface area, and nature of the material ${ }^{[10]}$.

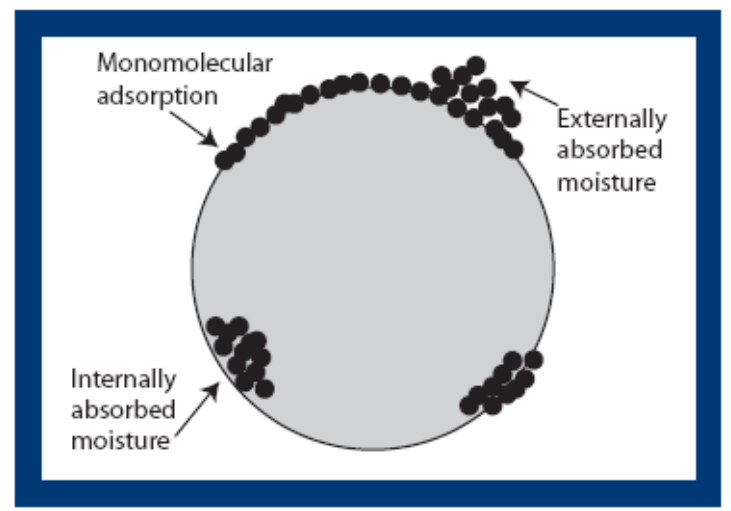

Figure 3: Various states of moisture ${ }^{3}$.

The particles come closer to each other on addition of more amount of liquid. Due to this, the void spaces within the granules are entirely eliminated. At this point, there is a bonding due to interfacial forces and intragranular forces. This state is known as capillary state, which is considered as an optimum strength required for the granules to give a tablet of good strength. Further addition of liquid results in droplet formation in which the particles are still held together by surface tension. However, such structures are weaker.

Effect of moisture content on the strength of the tablet can be known by four states ${ }^{3}$, namely, Pendular state, Funicular state, Capillary state, Droplet state. Figure 3 shows the various states of moisture around a particle.

\section{Experimental Procedure}

\section{Materials and Instrumentation}

The materials and their amounts required for the work were, Paracetamol powder $2 \mathrm{~kg}$, amigel $239.5 \mathrm{gm}$, maize starch $80.24 \mathrm{gm}$, potassium sorbate $7.98 \mathrm{gm}$ and water $400 \mathrm{~mL}$. The batch time was 20 minutes and it was divided in 5 time steps each of 5 minutes. Sample was collected after each 5 minutes, sieved with \#20 Mesh and the corresponding moisture content was measured for 10 minutes using a MJ33 Moisture analyser by Mettler Toledo at $100^{\circ} \mathrm{C}$. Figure 4 shows the block diagram of the procedure. Figure 5, Figure 6 and Figure 7 shows the different units operated during this case study work. 


\section{Chemical Engineering Research Bulletin 20(2018) 1-7}

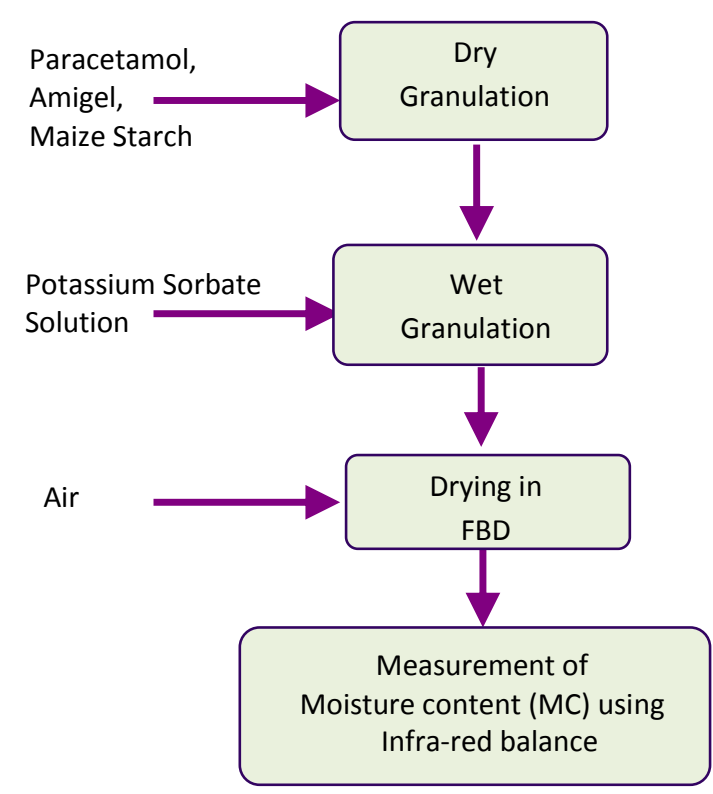

Figure 4: Process block diagram.

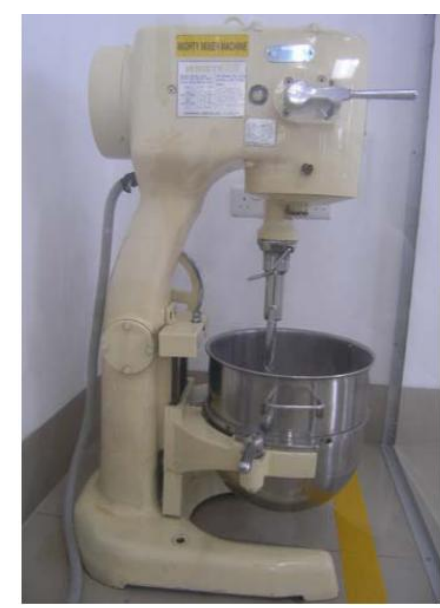

Figure 5: Mighty Mixer Granulator.

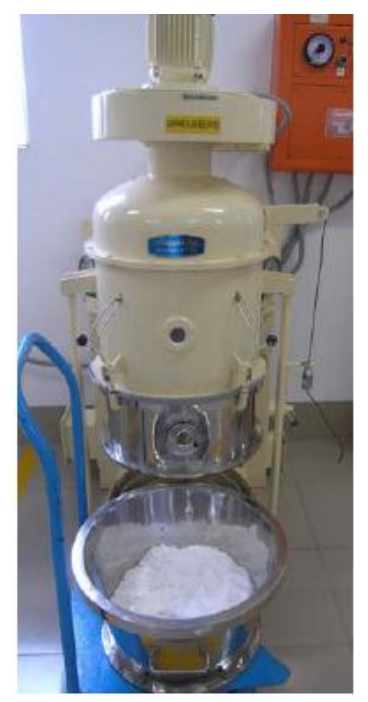

Figure 6: Sapphire Fluid Bed Dryer with wet granules loaded.

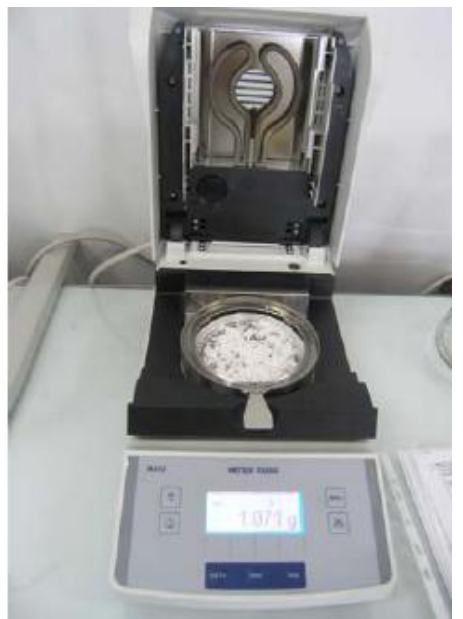

Figure 7: MJ33 Moisture Analyzer with sieved granules loaded.

\section{Results and Discussions}

The historical data sets were collected for six batches to identify the LTV perturbation model of the system. The required drying temperature was calculated using LTV model based ILC. The historical data, nominal data, desired MC and calculated ILC data are tabulated in Table 2 to Table 5 consecutively.

Table 2: Historical Data.

\begin{tabular}{|c|c|c|c|c|c|c|}
\hline \multicolumn{2}{|c|}{ Time (min) } & 0 & 5 & 10 & 15 & 20 \\
\hline $\begin{array}{l}\text { Batch } \\
\text { No. }\end{array}$ & $\begin{array}{l}\text { Drying } \\
\text { Temp. } \\
\left({ }^{\circ} \mathrm{C}\right)\end{array}$ & \multicolumn{5}{|c|}{ Moisture Content (\%) } \\
\hline 1 & 40 & 9.96 & 7.55 & 6.79 & 6.59 & 5.95 \\
\hline 2 & 42.5 & 9.61 & 7.4 & 6.32 & 6.22 & 5.00 \\
\hline 3 & 45 & 9.9 & 7.25 & 6.59 & 6.20 & 4.91 \\
\hline 4 & 47.5 & 9.92 & 6.96 & 6.07 & 6.07 & 4.63 \\
\hline 5 & 50 & 9.89 & 6.85 & 5.91 & 5.61 & 4.59 \\
\hline 6 & 52.5 & 9.76 & 6.68 & 5.61 & 5.16 & 4.49 \\
\hline
\end{tabular}

Table 3: Nominal Data.

\begin{tabular}{|l|c|c|c|c|c|}
\hline Time (min) & $\mathbf{0}$ & $\mathbf{5}$ & $\mathbf{1 0}$ & $\mathbf{1 5}$ & $\mathbf{2 0}$ \\
\hline $\begin{array}{l}\text { Drying } \\
\text { Temp. }\left({ }^{\circ} \mathbf{C}\right)\end{array}$ & \multicolumn{5}{|c|}{ Moisture Content (\%) } \\
\hline 55 & 9.85 & 6.77 & 4.85 & 4.71 & 4.46 \\
\hline
\end{tabular}

Table 4: Desired Moisture Content (\%).

\begin{tabular}{|l|c|c|c|c|c|}
\hline Time (min) & $\mathbf{0}$ & $\mathbf{5}$ & $\mathbf{1 0}$ & $\mathbf{1 5}$ & $\mathbf{2 0}$ \\
\hline $\begin{array}{l}\text { Moisture } \\
\text { Content (\%) }\end{array}$ & 9.5 & 5 & 4 & 3 & 2 \\
\hline
\end{tabular}




\section{Chemical Engineering Research Bulletin 20(2018) 1-7}

Table 5: Experimental ILC Data.

\begin{tabular}{|c|c|c|c|c|c|c|}
\hline \multicolumn{2}{|c|}{ Time (min) } & $\mathbf{0}$ & 5 & 10 & 15 & 20 \\
\hline $\begin{array}{l}\text { Batch } \\
\text { No. }\end{array}$ & $\begin{array}{c}\text { Drying } \\
\text { Temp. }\end{array}$ & \multicolumn{5}{|c|}{ Moisture Content (\%) } \\
\hline 1 & 58.28 & 9.96 & 6.90 & 5.64 & 4.39 & 4.15 \\
\hline 2 & 61.02 & 9.61 & 6.20 & 5.14 & 4.15 & 4 \\
\hline 3 & 63.91 & 9.9 & 6.77 & 5.11 & 4.07 & 3.88 \\
\hline 4 & 66.65 & 9.92 & 6.41 & 5.14 & 3.68 & 3.5 \\
\hline 5 & 69.91 & 9.89 & 5.95 & 4.92 & 3.80 & 3 \\
\hline 6 & 71.70 & 9.76 & 6.73 & 4.89 & 3.56 & 2.8 \\
\hline 7 & 73.90 & 9.85 & 5.11 & 4.07 & 3.88 & 2.4 \\
\hline 8 & 75.40 & 9.96 & 5.60 & 4.38 & 3.04 & 2.05 \\
\hline
\end{tabular}

Here, drying temperature is the input and moisture content (\%) is the output. Figure 8 shows the moisture content trajectories for different temperatures and Figure 9 shows how the final moisture content decreased gradually with the increase in drying temperature.

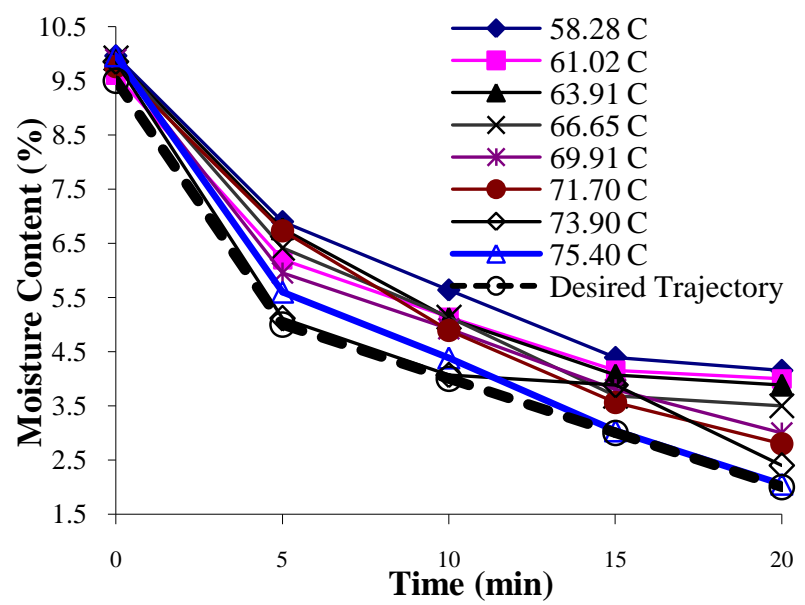

Figure 8: Trajectories of moisture content.

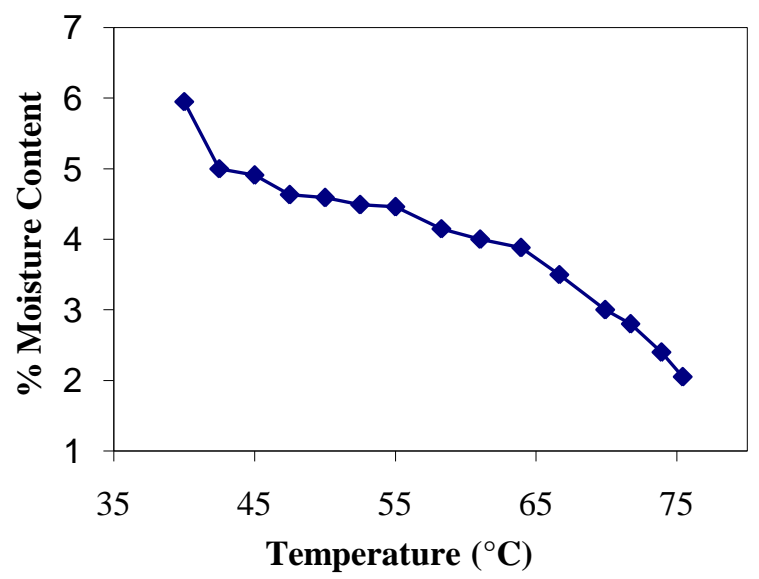

Figure 9: Final moisture content vs. temperature plot.
Figure 10 shows the sum squared error (SSE) values between the desired and actual MC trajectories. It took 7 batches to drop the SSE significantly and during the $8^{\text {th }}$ batch the result converged to the desired MC trajectory (See Figure 8 and Figure 9). The required temperature is $75.4{ }^{\circ} \mathrm{C}$. To confirm this drying temperature two additional batches were ran at $75.4{ }^{\circ} \mathrm{C}$ and these gives slight deviations in $\mathrm{MC}$ trajectories within acceptable limit.

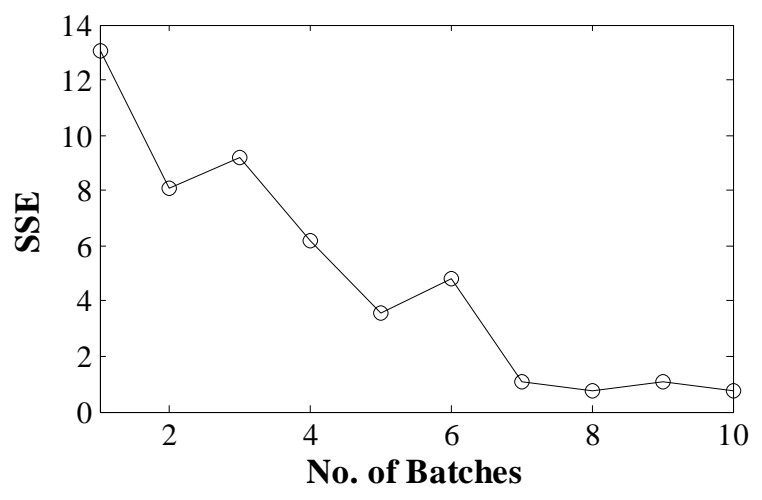

Figure 10: Tracking performance of ILC.

\section{Conclusions}

In the pharmaceutical industry, most products are manufactured using the wet granulation process. Wet granulation offers a wide range of capabilities for forming granules from the production of light granules to the production of very dense granules. More than $70 \%$ of the global industry's granulations are made using this method ${ }^{11}$. When a wet-granulation technique is employed, control of the residual moisture after the drying step is important for smooth tablet compression. Too low or too high moisture contents may influence the chemical and physical stability of the final tablet ${ }^{12}$.

In this paper the industrial case study in GlaxoSmithKline Bangladesh Limited, Chittagong, Bangladesh, to evaluate the proposed LTV perturbation model based ILC has been discussed. The work was focused on applying the LTV model based ILC to find out the correct temperature to be applied to obtain the desired final moisture content $(2 \%)$ in the tableting blend prepared for Parapyrol tablets in a pilot scale experimental set up. The results show that the moisture content converged to the desired one from batch to batch and after eight batches it reached the final result and demonstrated that the approach is able to converge to the desired profiles without the need of a detailed mechanistic process model. 


\section{Chemical Engineering Research Bulletin 20(2018) 1-7}

\section{Acknowledgement}

The author acknowledges the technical support by GlaxoSmithKline Bangladesh Limited, Chittagong, Bangladesh, Loughborough University, United Kingdom for a scholarship and PhD supervisor Professor Zoltan K. Nagy for giving the opportunity to undertake this research project.

\section{References}

1. Haywood, A. and Glass, B. (2011). Pharmaceutical excipients-where do we begin? Australian Prescriber, 34(4), pp. 112-114.

2. United States Pharmacopeia (2002). United States Pharmacopeia/National Formulary (USP29/NF24)., Rockville, MD: United States Pharmacopeia Convention Inc. Available via http://www.pharmacopeia.cn/v29240/usp29nf24sO_c 1151s87.html, accessed on 09-4-2018.

3. Nokhodchi, A. (2005). An Overview of the Effect of Moisture on Compaction and Compression. Pharmaceutical Technology, pp 46-66. Available via http://www.pharmtech.com/pharmtech/data/articlest andard/pharmtech/022005/141826/article.pdf, accessed on 09-4-2018.

4. Bhalani, K. P. (2010). Moisture Content Determination in Fluid Bed Dryer by Near Infrared Spectroscopy (NIRS). Available online at http://archivepharma.financialexpress.com/2010083 1/pharmaally09.shtml, accessed 8 March 2016.

5. Lee, J. H. and Lee, K. S. (2007). Iterative learning control applied to batch processes: An overview. Control Engineering Practice, 15, pp.1306-1318.

6. Sanzida, N. and Nagy, Z. K. (2013). Iterative Learning Control for the Systematic Design of Supersaturation Controlled Batch Cooling Crystallisation Processes. Computers and Chemical
Engineering, $\quad 59, \quad$ pp. $\quad 111-121$ http://dx.doi.org/10.1016/j.compchemeng.2013.05.02 7.

7. Chen, J., Sarma, B., Evans, J. M. B., and Myerson, A. S. (2011). Pharmaceutical crystallisation. Crystal Growth and Design, 11, pp. 887-895.

8. Nagy, Z.K. (2009). Model based robust batch-tobatch control of particle size and shape in pharmaceutical crystallization, in S. Engell, Y. Arkun (Eds.) Proc. of the 9th IFAC Symp. on Adv. Control of Chem. Proc. (ADCHEM), Istanbul, Turkey, July 12-15, pp. 200-205.

9. Xiong, Z. and Zhang, J. (2003). Product quality trajectory tracking in batch processes using iterative learning control based on time-varying perturbation models, Ind. Eng. Chem. Res., 42, pp. 6802-6814.

10. Dawoodbahai, S. and Rhodes, C.T. (1989). The Effect of Moisture on Powder Flow and on Compaction and Physical Stability of Tablets. Drug Dev. Ind. Pharm., 15 (10), pp. 1577-1600.

11. Tousey. M. D. (2002). The granulation process 101 , basic technologies for tablet making. Pharm. Tech. Tableting and Granulation. 2002. Available via http://www.techceuticals.com/The_Granulation_Pro cess_101.pdf, accessed on 09-4-2018.

12. World Health Organization (WHO) (2011). Revision of monograph on tablets-final text for addition to the international pharmacopoeia. Document QAS/09.324/Final. Available via http://www.who.int/medicines/publications/pharmac opoeia/Tabs-GeneralMono-rev FINAL_31032011.pdf, accessed on 09-4-2018.

Publisher: Department of Chemical Engineering, Bangladesh University of Engineering and Technology (BUET). Review \&Publication: A submitted original manuscript is taken into review only if the uniqueness is found to be more than $85 \%$ in plag-scanning and selected for publication by the complete acceptance from at least two reviewers out of three. Home Page: http://www.banglajol.info/index.php/CERB. Indexed by Chemical Abstract Service (CAS), CEABA-VtB, Google Scholar, Scopus and DOAJ. 